\title{
Teaching English: An afresh sophisticated technique to cultivate digital native learners' vocabulary by utilizing seesaw media as digital literacy
}

\author{
Ikrar Genidal Riadil \\ English Education, Universitas Tidar, Indonesia \\ 1ikrargenidal21@gmail.com \\ *) correspondence: ikrargenidal21@gmail.com
}

\begin{abstract}
In the modern and digital era, digital native's learners are conceived into an era of digital networking. It keeps everything connected to technology. Digital natives with digital technical expertise and abilities which can theoretically be utilized for improved learners' interaction in the classroom. The government has began to vigorously increase the literacy culture in schools by doing reading literacy. Teachers will be willing to provide an precedent by developing a community of literacy at school. Increased classroom reading atmosphere also improves vocabulary for learners studying English. The Seesaw Media implementation may also help learners to insert allusions to enhance scientific knowledge as a regulatory framework for learning. The aim of this research was to discern the use of Seesaw as the media of literacy to cultivate learners' vocabulary. This research pursued to answer two research questions; (1) does Seesaw Media helps learners to improve their reading ability? And (2) what are the impacts of Seesaw Media application on the learners on developing vocabulary? The methods used by the researcher were; firstly, the researcher distributed the questionnaire with the English learner's. Secondly, the researcher assessed the feedback from the respondents. Thirdly, the researcher sought the response to the learners on the effect of reading ability by using Seesaw. This research has used descriptive qualitative to conduct the research study. This result of the research has shown the Seesaw Media helped learners to improve their reading ability.
\end{abstract}

Keywords: seesaw media; digital; literacy; vocabulary; teaching English

\section{INTRODUCTION}

Language is a crucial element of the human being. By attempting to learn, people can interact with one another, get information from one to the other, and communicate. Language has a major role to play in human life in creating a relationship in their surroundings. Yet another scholar claims that language is widely used in interaction among people who do not share the same first (or even second) language. (Harmer, 2007). It indicates that language is very pivotal to learn in human life.

In additament, the 2013 curriculum is a new curriculum in Indonesia with a low amount of enthusiasm in writing and reading. The government has undertaken a literacy program in schools through the Ministry of Education and Culture. The system was established on the basis of the Kemendikbud (2015) Minister of Education and Culture Number 21 of 2015 on Character Growth. The aim of this program is to get the learners used and motivated to want to read and write to maintain character. The School Reading System is also projected to develop students with strong literacy skills. As a result, the literacy initiative was also expanded in 2017 by beginning to integrate it into schooling by changes to the 2013 Curriculum. Literacy is communicating by clearly interpreted hieroglyphs, not by audio and signalling networks. The graphical annotation involves the writing of the alphabetmediated text, scripted by (Syahriyani, 2010: p.70). The expansion of literacy cultural environment is crucial for people to accelerate their lives, because a deeply entrenched cultural heritage of literacy will make people habituated to being critical and scrutinizing what's going on around them (Sakti, 2012: 
p.259). Moreover, the literacy cultural heritage in Indonesia is exceedingly low compared to other countries. There are several factors that determine low literacy culture.

In terms of ideas, it can be distinguished from aspects in or out of the school environment. In a non-school setting, for instance, the home atmosphere often has a major effect on somebody's reading interest. The enthusiasm in information technology is growing extremely quickly, but it is used for activities that do not encourage literacy. The low spending power of books is a factor, too. The aspects in the school environment are also dynamic, such as inadequate infrastructure to sustain literacy activities, such as a good library, and a collection of books that are sufficiently accurate and diverse. A further aspect is learning circumstances that do not empower learners to study books outside of textbooks. Classroom learning is always an instructor-centered or merely a knowledge sharing exercise where learners are only packed with facts or experience by the instructor and are never encouraged to explore or resolve problems relating to the topics studied such that learners are not inspired to pursue facts from certain outlets and are not prepared to improve awareness by reading. The image of an educator who is considered to be a role model of reading and writing cultural identity has still not yet been able to encourage learners to be involved in developing their literacy community. The culture of reading and writing for teachers is central to improving their trust. Teachers who have a high culture of literacy have a large and powerful reliability of the results of their work.

Consequently, in view of the increasing requirements of teacher professionalism, literacy culture can be one way of improving their skills, competencies and professionalism. This also has a significant impact on the level of pleasure of the learners in their deliberation with the teacher. A good culture of literacy could provide a comprehensive insight for an educator. Moreover, as time passes, there is a need for information that is always up to date is needed for a teacher to know the latest issues to be able to answer every question from learners. In addition, literacy culture can enhance teacher competence, along with all the requirements of a high level of teacher professionalism. The vastness of the teacher's expertise makes it easier for learners to instruct. If the educator could be a great student, they could also be a strong writer. The variety of vocabulary enables the educator to express his or her opinion in a prolonged and clean manner. Besides, there's The adjustments to the 2013 Curriculum, that included an improvement in the literary culture of school, have required teachers to create a strong literary culture. This is a preservative in order for the teacher to be able to sustain the advancement of science and technology and to equilibrium the different types of learners in the classroom. The lack of instructors as role models in the school literacy campaign is due to the low culture of teaching literacy.

Consequently, there are plenty of teachers do not still see the meaning and significance of literary culture for the consistency of science. Although the educator's reading and writing cultural heritage can also tend to maintain teachers in enhancing their knowledge and skills that can be used for classroom learning. The low level of teacher literacy is caused by reading and writing is not a need or a means for leaders to encourage themselves. Without this, it's hard for someone like an educator to want to read and write. In particular, teachers of the history of reading and writing society need to incorporate contextual information and references. Another reason, which is often brought up, is busy (Apandi, 2016). Messiness is the explanation why teachers are more frequently questioned to be the explanation why literacy culture is not a priority for them. The increasing number of educational activities related to the implementation and assessment of learners also increases the level of teacher activity. According to them, it doesn't take time to read books or write. If they also need to spend time taking care of the house and family after returning home, so no portion of time for teachers to read books or write after activities at school.

In this modern era, educators and students need to be capable of adapting to the era. One of them is that students and educators are presumed to grasp foreign languages in global communication and to be able to use technology in everyday life. Language is a message, emblem, or device used to convey knowledge in a spoken or written manner. Language has a deep association with a daily conversation. Conversation can be widely understood by using a language they understand. Language could be termed a framework that individuals used to interact with one another and to share 
information. Language category encompasses speaking, writing, measurements were performed, or moving the body. The simple part of the language is sound, as well as every language has its own grammar. It implies that various languages have specific laws. These rules in grammar are used to regulate the role of the language to communicate or create knowledge and to provide sense to the phrases.

As a human being, human beings learn and tend to speak at least one language. The first language as our mother tongue, the language we hear as we grow up, and another language as our second language. These second languages could be obtained from our environment or from a new environment around us. When anyone wants to understand both the second language (SL) and the international language (FL) is not as seamless as possible. It also takes a great deal of work to grasp, introduce a foreign language, indulge in studying and build expertise because every language has its own structures and grammatically (Basurto Santos, Alarcón, \& Pablo, 2016: p.1). This is not completely mistaken to learn new things about language, especially when learning a foreign language, to be encouraged and self assured to be using a foreign language in a framework where a foreign language is not used outside the classroom. According to Finegan \& Chaika (1985), Individuals are expected to accomplish their skills and knowledge not only in terms of linguistic skills, but also in terms of adequate communicative competence and communication of any foreign language. Conversely, obtaining the ability to understand how to speak in a foreign language is not a benchmark for being able to speak a foreign language. Another juncture that should be made in order to be successful to use a foreign language in communication is to pronounce words correctly, use the correct grammatical, have a rich vocabulary and understand how to use them in speaking.

However, according to Nur \& Riadil (2019) also stated that the digital learners are digital native generation which uses a digital learning tool where teacher and learners alike can create their own interactive timelines. Many new social features introduce collaboration and engagement between learners. Vocabulary is another of the key elements that plays a crucial role in language. Vocabulary is crucial because someone will be able to interact well if the interlocutor understands every word that we want to express. Fluency and willingness to use a range of words will often help you appear confident and mastering the language. Since acquiring a new language, in fact a foreign language, especially the foreign language is not simple many people feel reluctant to learn English and that makes their vocabulary not develop. Whereas, in the current era, there are many applications can be used to learn and be able to enrich the vocabulary. One of them is that they can use an application called Seesaw Media. Moreover, online media look to incorporate new technologies into advising practice. Learners increasingly to contact via email, text messaging, and instant messaging rather than meet the teacher in the offices. Digital native does not see memorizing information as an education. With instant gratification avenues such as YouTube, IM, chat rooms, and social networking sites and WiFi hand-held PDA's with instant internet access.

Consequently, by using the application because one reason is that the future teacher will face digital native learners at the moment. We label them that besides living in the digital era, most learners have lately very often brought their own smartphones wherever and whenever they go. Thus, using an application, many of which are in the smartphone, is efficient enough. The impact of using a smartphone on learners to improve their vocabulary learning.

Seesaw Media is an Instructional Content Platform that amplified reading engagement and learning in every subject. It is an application and web which provide reading digital platform to help people to read some articles. It provides some articles from a variety of genres In the Seesaw Media helps the readers to find some articles which they want. They could find anything there. The features given by it help the readers to improve their reading skills because they could read anything that is their favorite. The Seesaw Media application can help the teachers also the learners to add references to enrich science as a provision for learning.

Then, after students continue to take the quiz and accumulate enough points, the website lets them find articles that better match their particular educational level, so that they can grasp the articles but are still encouraged to keep going forward. In comparison, most English teachers in developed 
countries have significant issues with poor literacy in computer and internet use (Son, Robb, \& Charismiadji, 2011). In short, digital-native learners are now in the digital era and will also work through the use of digital technologies. In addition, a radical change in education policy is proposed to implement massive e-learning in Indonesian schools. Based on these social phenomenon, the researcher is interested in analyzing certain phenomena-related problems. As a result, the research problems are set out as follows, what kind of media you use in speaking learning classes and for learners, in your opinion, what is the effect of the habit of digital natives, most of whom have access to seesaw media in their speaking class.

\section{METHODS}

Qualitative research was used in this research. Patton \& Cochran (2007) explained qualitative research is characterized by its aims, which relate to understanding some aspect of social life, and its methods which generate words, rather than numbers, as data for analysis. Qualitative research is understanding of social phenomenon based on participant's point of view. In order to increase information into a certain phenomenon, such as an environment, a process, or a belief. The data were collected by giving questionnaires to participants. The data collection procedures of this study were started by giving the questionnaire, asking the participants to fill in the questionnaire and finally the researcher compiled the questionnaire that had been answered.

This method was influenced by (Cam \& Tran, 2017). After the data had been collected, it would be analyzed and recognized. Like what Cam \& Tran (2017) stated that the questionnaire was a quite useful collection method because researcher could reach many participants and respondents in a short time and it did not need cost so much. This research aimed to distinguish the usage of Seesaw Media as the media of literacy to enrich learner's vocabulary. The object of this research was the college learners.

To begin this research, the researcher took three steps to answer questions in this research.

1. Created the questionnaire and then shared it with the college learners.

2. Evaluated the responses from the respondents.

3. Found out the answer about the impacts of Seesaw Media to the learners.

After collecting the respondents' answers, the data were analyzed to answer the research questions. The arrangement of this study consists of:

1. Research Subject

The research subjects were learners in 2nd semester to 6th semester of English Department Learners Tidar Magelang University, Central Java with 50 respondents.

2. Research Place

The study was conducted at Tidar University Magelang, Central Java.

3. Research Time

This research was conducted in the year of 2020

In addition, the questions raised were in English, although some of the reasons the respondents answered were in Indonesian. Although it did not have an impact on the research. Besides, they could voice their opinion easily and freely. Not only did the questionnaire not allow the respondents to write their real name. They could write their real name or the initial name. Then the researcher would name them as respondent one, two, and so on and it does not impact the data that had been collected.

\section{RESULTS AND DISCUSSION}

This segment distinguishes the result of this study, which the researcher discussed with undergraduate students in Indonesia. This questionnaire consists of twelve questions which the researcher considered to be the finding of this research questionnaire.

The majority of respondents are in the English Department. The reason why the researcher focuses on English Department Leraners is that the researcher knows that most English Department learners are familiar with a platform that could improve their English skills. Any of the respondents 
often come from other countries. It means that several college learners who are from other majors also know about the platform which could improve the ability to learning English. Starting from semester 2-6 respondents answer the questions. In total 50 questionnaires are collected from the college learners.

In order to collect the data needed, the researcher makes questions of questionnaire as can be seen below:

Table 1. Questions of Questionnaire

\begin{tabular}{|c|c|}
\hline No & Question \\
\hline 1 & Do you know Seesaw Media? $(\mathrm{Y} / \mathrm{N})$ \\
\hline 2 & Do you like to visit this reading platform? $(\mathrm{Y} / \mathrm{N})$ \\
\hline 3 & Do you know the sections of all which available in the Seesaw Media? $(\mathrm{Y} / \mathrm{N})$ \\
\hline 4 & Which section do you like the most? (give reason) \\
\hline 5 & $\begin{array}{l}\text { Do you think that Seesaw Media help you to improve you reading? }(\mathrm{Y} / \mathrm{N} \text { and give } \\
\text { reason) }\end{array}$ \\
\hline 6 & $\begin{array}{l}\text { Do you think that Seesaw Media help you to increase your vocabulary? }(\mathrm{Y} / \mathrm{N} \text { and } \\
\text { give reason) }\end{array}$ \\
\hline 7 & What is the advantages of using Seesaw Media? \\
\hline 8 & What is the disadvantages of using Seesaw Media? \\
\hline 9 & Would you still use Seesaw Media to help you to improve your reading skills? $(\mathrm{Y} / \mathrm{N})$ \\
\hline
\end{tabular}

Table 2. The Result of Questionnaires

\begin{tabular}{ccc}
\hline $\begin{array}{c}\text { Numbers' of } \\
\text { Questionnaire }\end{array}$ & Yes & No \\
\hline 1 & 43 participants $(82,7 \%)$ & 9 participants $(17,3 \%)$ \\
2 & 42 participants $(80,8 \%)$ & 10 participants $(19,2 \%)$ \\
3 & 30 participants $(57,7 \%)$ & 22 participants $(42,3 \%)$ \\
4 & 43 participants $(82,7 \%)$ & 9 participants $(17,3 \%)$ \\
5 & 45 participants $(86,5 \%)$ & 7 participants $(13,5 \%)$ \\
6 & 43 participants $(82,7 \%)$ & 9 participants $(17,3 \%)$
\end{tabular}

The first and second questions related to how well the respondents know the media in Seesaw. The first question asked whether the respondents were familiar with the Seesaw Media or not. Approximately $84.3 \%$ of the total respondents said they knew about Seesaw Media and 15.7\% said they did not know about Seesaw Media. The second issue concerns the role of Seesaw Media. Most of the respondents are aware of Seesaw Media as a reading platform. Nevertheless, several of them who do not know about Seesaw Media have said that they do not even know about Seesaw Media's function as a reading platform. Most of the students who answer yes are from the English Department. Also, some of them do not seem to have known this reading platform.

There are so many sections in Seesaw Media. Sections here mean the genre of each article that is available. Such as war and peace, youth, technology, rule, fitness, recreation, music, and opinion. Anything in these parts is covered in each portion. For example, if readers choose health as a section, they will find out all articles about health. By sharing the questionnaire, the researcher knows that most of the college learners who understand the using of the Seesaw Media already know every section in this reading platform. 58,8\% of the total respondents know about the sections in Seesaw Media and about $41,2 \%$ do not know about it. 
Arts are the most preferred segments chosen by the respondents. For the explanations in the panel, the respondents have a clear opinion as to why they prefer these pieces. The opinion section has become the second most preferred section chosen by the respondents and the science section becomes the third. By reading Seesaw Media, the respondents answer the next question "do you think Seesaw Media helps you to improve your reading?". Most of the respondents who know Seesaw Media well answer yes.

The purpose they said they were responding because they could interpret anything they needed to say. In addition, in this question, the researcher discovers out that improving someone's reading is giving them the text they want. The other reasons why they believe that Seesaw Media could enhance their reading are, by reading an article in Seesaw Media, giving them a piece of additional information and Seesaw Media also has much content to improve their reading.

The next question is about vocabulary. $86,3 \%$ of the respondents said that by reading articles from Seesaw Media could improve their vocabularies. The possible reason why Seesaw Media could boost their reading is that Seesaw Media has created several stories with new vocabulary. Most of the respondents claimed they acquired new vocabulary by reading it as they noticed different terms online. Also, in total $13,7 \%$ of respondents said that Seesaw Media does not help them to improve their vocabulary because they do not know the Seesaw Media.

Each application has many benefits and drawbacks. Through such a questionnaire, the researcher finds that the users of Seesaw Media are already aware of the benefits and drawbacks. Initially, the potential benefits of using Seesaw Media are that it could enhance the reader's ability to read any genre and style they like. It gives a plethora of articles so that readers can choose their absolute favourite articles. The participants also said that they could improve their English skills in Seesaw Media. Next, the drawbacks of this application are that we need to join the course to take the quiz sections. As an online platform, Seesaw Media needs to have a strong internet connection. By the answer of the respondents said that they will still use Seesaw Media to improve their reading and help them to enrich the vocabularies.

\section{CONCLUSION}

The aim of this research was to seek that Seesaw Media helped learners enhance their reading and strengthen their vocabulary with Seesaw Media. In this research , the researcher points out that helping learners to develop their reading is by giving them a text by genre and style they like. Learners did not like it when they were attempted to push to read something that wasn't their favorites. In addition to enriching learners' vocabulary, reading a text may help them to enhance their vocabulary. By comprehending the responses of the respondents, the researcher knew that two steps had been taken to strengthen vocabulary. First, they had to discover a language that they didn't realize they were searching for sense in the dictionary. The result of this research has therefore shown that Seesaw Media has helped learners to improve their reading ability and enrich their vocabularies.

\section{REFERENCES}

Apandi, I. (2016). Guru dan Budaya Literasi. Retrieved January 4, 2020, from kompasiana.com website: https://www.kompasiana.com/idrisapandi/568cf007f77a614115a384e2./guru-danbudaya-literasi

Basurto Santos, N. M., Alarcón, M. M. H., \& Pablo, I. M. (2016). Fillers and the development of oral strategic competence in foreign language learning. Porta Linguarum, 2016(25), 191-201.

Cam, L., \& Tran, T. M. T. (2017). An evaluation of using games in teaching English grammar for first year English-majored students at Dong Nai Technology University. International Journal of Learning, Teaching and Educational Research, 16(7), 55-71. Retrieved from https://pdfs.semanticscholar.org/ea44/48f1c6cbb8dab7420abbd20a993a86728206.pdf

Finegan, E., \& Chaika, E. (1985). Language: The Social Mirror. Language. https://doi.org/10.2307/414431

Harmer, J. (2007). The Practice of English Languag Teaching. 394-409. 
Riadil, I.G.

Kemendikbud, R. I. (2015). Penumbuhan Budi Pekerti.

Nur, M. R. O., \& Riadil, I. G. (2019). Digital Natives' Preference in 4 . 0 Speaking Learning Class. 3rd English Language and Literature International Conference (ELLiC), 3, 202-208.

Patton, M., \& Cochran, M. (2007). A Guide to Using Qualitative Research Methodology. In Medecins Sans Frontieres. Retrieved from http://msf.openrepository.com/msf/handle/10144/84230

Sakti, P. (2012). BUDAYA LITERASI SEBAGAI RELASI DUNIA : bersaing di tingkat dunia . Pasalnya, posisi pemuda begitu strategis mengingat daya nalar revolusioner yang tumbuh dicetuskan setelah dan sebelum proklamasi kemerdekaan. Prosiding Seminar Internasional Multikultural \& Globalisasi 2012, 258-274.

Son, J.-B., Robb, T., \& Charismiadji, I. (2011). Computer literacy and competency: a survey of Indonesian teachers of English as a foreign language. Computer-Assisted Language Learning Electronic Journal (CALL-EJ).

Syahriyani, A. (2010). Optimalisasi budaya literasi di kalangan mahasiswa: upaya meretas komunikasi global. Jurnal UI Untuk Bangsa Seri Sosial Dan Humaniora. 